\title{
MEMBANGUN SISTEM INFORMASI PERPUSTAKAAN DIGITAL BERBASIS WEB
}

\author{
Ispandi \\ Teknik Informatika, STMIK Nusa Mandiri \\ email: ispandi.ipd@nusamandiri.ac.id
}

\begin{abstract}
ABSTRAK
Pemanfaatan fasilitas internet yang baik dapat mempermudah masyarakat dalam melakukan aktivitas, seperti kegiatan membaca buku yang berguna untuk menambah wawasan dan pengetahuan. Akan tetapi terkadang terhambat pada biaya untuk membeli buku yang diinginkan, oleh karena itu sistem perpustakaan merupakan hal yang tepat untuk masyarakat dalam menambah wawasan melalui buku tanpa perlu mengeluarkan biaya. Hasil permasalahan yang penulis dapatkan pada perpustakaan konvensional adalah diharuskannya meluangkan waktu untuk pergi ke perpustakaan dan mengeluarkan biaya untuk pergi ke perpustakaan bahkan hanya untuk menjadi anggota perpustakaan, oleh karena itu penulis tertarik untuk menyelesaikan permasalahan tersebut dengan membuat sistem informasi digital library berbasis website yang dapat diakses dimana saja dan kapan saja tanpa mengeluarkan biaya. Pembuatan website ini menggunakan framework PHP Codeigniter yang dapat membantu user maupun pengelola dalam membaca, meminjam dan mengembalikan buku. Metode yang digunakan pada pengembangan perangkat lunak ini menggunakan model aterfall yang terdiri dari lima tahap yaitu Requirement Analysis, System Design, Implementation, Integration \& Testing, Dari data yang di kumpulkan mengenai e-library siswa siswi yang mecoba aplikasi e-library menerangkan bahwa $84,8 \%$ siswa-siswi dan mahasiswa menyukai program elibrary Karena membatu mereka dalam membaca tanpa harus ke pepustakaan. Dengan adanya layanan e-library diharapkan banyak orang yang gemar membaca.
\end{abstract}

Kata kunci: Perpustakaan Digital, Buku, Peminjaman, Pengembalian

\begin{abstract}
The use of good internet facilities can make it easier for people to carry out activities, such as reading books that are useful for adding insight and knowledge. But sometimes it is hampered by the cost of buying the desired book, therefore the library system is the right thing for the community to add insight through books without the need to spend money. The results of the problems that the authors get in conventional libraries are required to take the time to go to the library and spend to go to the library even just to become members of the library, therefore the authors are interested in resolving these problems by making a website-based digital library information system that is accessible anywhere and anytime without spending money. Making this website uses the PHP Codelgniter framework that can help users and managers to read, borrow and return books. The method used in software development uses a waterfall model which consists of five stages, namely Requirement Analysis, System Design, Implementation, Integration \& Testing, From the data collected about e-library students who try the e-library application explain that $84,8 \%$ of students and students like the e-library program because they help them read without having to go to the library. With the e-library service, it is expected that many people like to read.
\end{abstract}

Keywords: E-Library, Book, Borrow, Return

\section{PENDAHULUAN}

Dalam dunia pendidikan membaca buku merupakan hal yang penting dikarenakan dengan membaca buku maka pengetahuan akan bertambah dan juga akan banyak ilmu yang di dapatkan. Buku merupakan jendela ilmu dan gudang ilmu. Contohnya saja untuk mengetahui apa yang ada pada luar angkasa, kita tidak perlu untuk pergi ke luar angkasa untuk mengetahuinya, cukup hanya dengan membaca buku mengenai luar angkasa saja dan kita akan mendapatkan pengetahuan yang di inginkan dikarenakan isi 
buku berdasarkan dari beberapa penelitian [1]. Tentunya begitu banyak buku tertata dengan rapih pada toko buku, pasti terkadang ada keinginan untuk membeli buku tersebut. Tapi terkadang adanya permasalahan di biaya. Maka dari itu, dibuat sistem perpustakaan yang berguna untuk masyarakat dalam menambah ilmu pengetahuannya tanpa perlu mengeluarkan biaya [2].

Peranan perpustakaan sangat berpengaruh untuk pembelajaran siswa maupun mahasiswa dalam menambah ilmu pengetahuan dan diperlukannya profesionalisme bagi pihak pengelola perpustakaan agar jalannya sistem perpustaakan itu sendiri dapat dirasakan manfaatnya oleh pembaca. Pada ilmu pengetahuan dan teknologi saat ini mengalami perkembanggan yang dinamis dan diharapkannya dengan kemajuan teknologi saat ini untuk pengolahan data bisa menjadi efektif, efesien dan juga akurat [3].

Banyak perpustakaan saat ini masih bersifat konvensional yang juga memiliki berbagai kendala dan permasalahan dari segi tempat maupun waktu baca yang dibatasi. Pengelolaan data yang masih menggunakan cara konvensional tersebut dapat menimbulkan masalah. Proses pencarian data buku dilakukan dengan membuka kembali perhalaman buku inventaris sehingga membutuhkan waktu yang cukup lama[4]. Selain itu, proses pembuatan laporan seperti laporan rekapitulasi data buku dan laporan daftar peminjam juga harus mengecek per halaman buku inventaris dan menyalinnya kembali. Akibatnya, butuh waktu lama dalam melakukan rekap data dan menyusun laporan. Hal ini yang membutuhkan suatu perubahan sistem dalam perpustakaan yang masih bersifat manual ke sistem berbasis komputer [5].

Maka dari itu diperlukannya perpustakaan digital yang bermaanfaat untuk masyarakat yang tidak perlu meluangkan waktunya untuk ke perpustakaan untuk membaca buku. Secara ekonomis perpustakaan digital lebih meringankan bagi masyarakat karena untuk membaca di tempat perpustakaan konvensional diperlukannya modal transportasi dan juga waktu, sedangkan perpustakaan digital dapat diakses melalui internet secara gratis dan pemberian sumber-sumber pustaka akan lebih banyak dari perpustakaan konvensioanal [6] bisa mengikuti perkembangan teknologi yang ada.

Tabel 1. Rincian Analisis Masalah Sistem Informasi Perpustakaan Digital

\begin{tabular}{|c|c|c|c|c|}
\hline \multicolumn{3}{|c|}{ No Analisis Masalah dan Pengaruh } & \multicolumn{2}{|c|}{ Tujuan Pengembangan Sistem } \\
\hline & Masalah & Penyebab dan Pengaruh & Tujuan Sitem & Batasan Sistem \\
\hline 1 & $\begin{array}{l}\text { Kesulitan } \\
\text { menemukan data } \\
\text { peminjaman dan } \\
\text { pengembalian buku }\end{array}$ & $\begin{array}{l}\text { Sistem yang masih } \\
\text { manual membuat staf } \\
\text { perpustakaan harus } \\
\text { mencari secara manual } \\
\text { transaksi sebelumnya. }\end{array}$ & $\begin{array}{l}\text { Memudahkan } \\
\text { proses pencarian } \\
\text { data peminjaman } \\
\text { buku }\end{array}$ & $\begin{array}{l}\text { Sarana dan } \\
\text { prasarana } \\
\text { terbatas }\end{array}$ \\
\hline 2 & $\begin{array}{l}\text { Kurang efektifnya } \\
\text { pencatatan } \\
\text { peminjaman dari } \\
\text { segi waktu }\end{array}$ & $\begin{array}{l}\text { Dengan sistem yang } \\
\text { masih manual } \\
\text { menyebabkan pengguna } \\
\text { menghabiskan waktu } \\
\text { yang cukup lama untuk } \\
\text { mencatat peminjaman. }\end{array}$ & $\begin{array}{l}\text { Mempersingkat } \\
\text { proses peminjaman }\end{array}$ & $\begin{array}{l}\text { Sarana dan } \\
\text { prasarana } \\
\text { terbatas }\end{array}$ \\
\hline
\end{tabular}

Yang melatar belakangi penelitian ini adalah untuk mencari data peminjam satu minggu lalu staf harus membuka daftar buku peminjam terlebih dahulu, lalu mencari nama peminjam dan menyesuaikan buku dengan yang tertulis dan kemudian menghitung denda jika terlambat. Hal ini tentu menyulitkan staf perpustakaan dan anggota. Waktu yang dimiliki siswa untuk berkunjung ke perpustakaan hanyalah waktu istirahat jam sekolah, sehingga butuh proses yang cepat pula apabila ingin memberikan pelayanan yang baik kepada pengguna.

\section{METODE PENELITIAN}

Metode yang digunakan pada pengembangan system informasi perpustakaan digital ini menggunakan proses SDLC (System Development Life Cycle) yaitu dengan model waterfall model waterfall [7]. Model waterfall merupakan model yang dikembangkan untuk pengembangan perangkat lunak secara sistematis dari satu tahap ke tahap yang lainnya seperti air terjun. Model ini mengusulkan pendekatan kepada pengembang perangkat lunak yang sistematika dan sekuensial yang dimulai dari sistem pada seluruh analisis, desain, kode, pengujian, dan pemeliharaan yang terdiri dari lima tahap [7], tahapan pertama yaitu Indentifikasi masalah : Pada tahap awal ini penulis melakukan analisa terhadap kebutuhan dalam membuat rancangan sistem informasi digital library. 
Pada tahap ini di lakukan wawancara dengan beberapa anggota perpustakaan di sekolah SMA untuk mencari permasalahan dan kebutuhan teknologi di perpustakaan yang bersifat konvensional. Pada tahapan kedua dilakukan pengumpulan data : di tahap ini dilakukan wawancara dengan aministrasi perpustakaan konvensional untuk mengumpulkan data perpustakaan, data yang di kumpulkan adalah proses peminjaman buku sampai dengan pengembalian buku. Tahap ketiga yaitu Perancangan Sistem: Pada tahap ini dilakukan proses system design dengan membagi kebutuhan perangkat keras (hadware) dan perangkat lunak (software). Proses ini terfokus pada rancangan antar muka, rancangan basis data, dan rancangan struktur navigasi. Rancangan antar muka meliputi rancangan untuk admin dan user. Tahap keempat yaitu Implementation : Pada tahap ini dilakukan pendeskripsikan implementasi. Yaitu pembuatan Sistem Informasi Perpustakaan sesuai dengan rancangan yang sudah di buat di perancangan system. Kemudian Semua fungsi-fungsi pada web harus diujicobakan. Agar web tidak error, perlu diadakan sosialiasi kepada pengguna web untuk memberikan petunjuk pengguna dan menggantisipasi terjadinya kesalahan dalam penggunaannya dan hasilnya harus benar-benar sesuai dengan kebutuhan dan berharap masyarakat dapat menggunakan situs dengan baik. Tahap kelima atau tahapan yang terakhir yaitu pengujian system : pada tahap ini dilakukan pengujian system untuk mengetahui dampak system informasi bagi perpustakaan yang masih konvensional apakah sudah sesuai dengan Sistem informasi perpustakaan digital. Model Fungsional Model fungsional perangkat lunak digunakan untuk menjelaskan bagaiaman gambaran umum dari perangkat lunak yang akan dikembangkan yaitu UML (Unified Modeling Language) adalah bahasa grafis yang digunakan untuk memvisualisasikan, menentukan, membangun dan mendokumentasikan artifak dari sistem perangkat lunak.

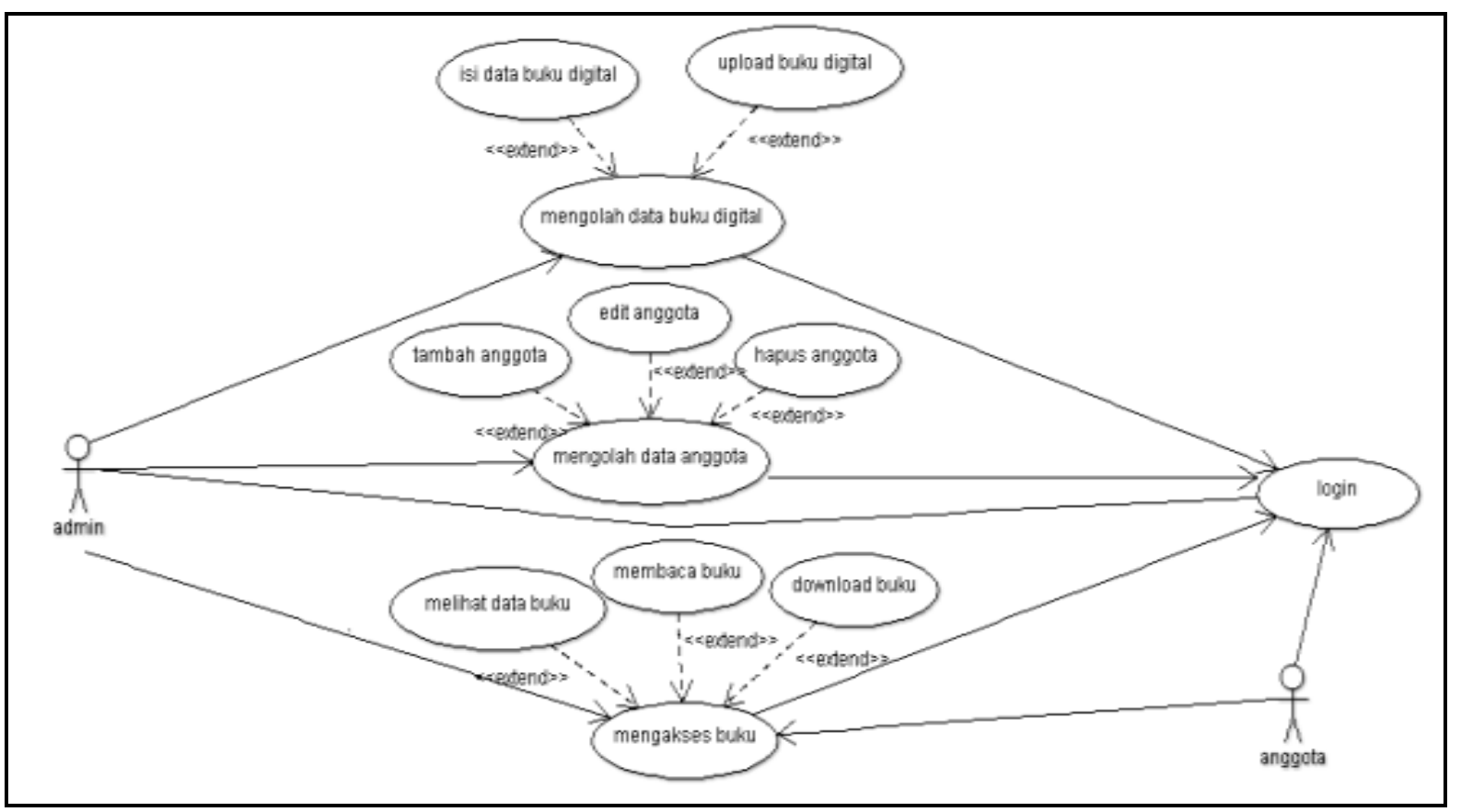

Gambar 1. Use Case Diagram Sistem Informasi Perpustakaan Digital

\section{HASIL DAN PEMBAHASAN}

Spesifikasi Perangkat Keras Sistem Informasi perpustakaan digital ini dikembangkan pada lingkungan perangkat keras komputer (laptop) yang memiliki spesifikasi sebagai berikut. (1) Processor Intel core i5 (2) RAM 4 GB (3) Kartu Grafis Nvidia GeForce (4) Monitor 14 inch dengan resolusi 1366 x 786 px. kemudian pada (b) Spesifikasi Sistem Informasi perpustakaan digital ini dikembangkan pada lingkungan perangkat lunak sebagai berikut. (1) Sistem Operasi Microsoft Windows 10 Pro 64-bit. (2) Bahasa pemrograman Java, XML, PHP, HTML5, CSS3, JavaScript dan MySQL. (3) Database server package yang digunakan adalah XAMPP versi 3.3.4. (4) Google Chrome browser. (5) Text editor Sublime Text.

Tahapan analisa kebutuhan [9] adalah tahap untuk mengidentifikasi apa saja yang diperlukan dan dibutuhkan oleh para pengguna. Dalam hal ini pengguna dapat dibedakan menjadi dua, yaitu:

a) Analisa Kebutuhan User 
User dapat melihat koleksi buku yang ada di menu categories, User dapat meminjam, membaca, mengembalikan dan menambah buku, User dapat membaca, mengubah dan menghapus buku yang telah di tambahkan, User dapat menerima atau menolak buku yang bersifat private kepada user, lain yang ingin meminjam buku, User dapat mengubah profile dan password, User dapat mendapatkan notifikasi dan melihat notifikasi. User dapat melihat laporan peminjaman dan pengembalian buku yang sudah di tambahkan.

b) Analisa Kebutuhan Admin

admin dapat menambah, mengubah dan menghapus data admin. Admin dapat menambah, mengubah dan mengapus data category, admin dapat melihat, mengubah dan menghapus data books, admin dapat mengubah dan menghapus data borrow. admin dapat mengubah dan menghapus data return. admin dapat melihat dan mencetak report books, report borrow dan report return

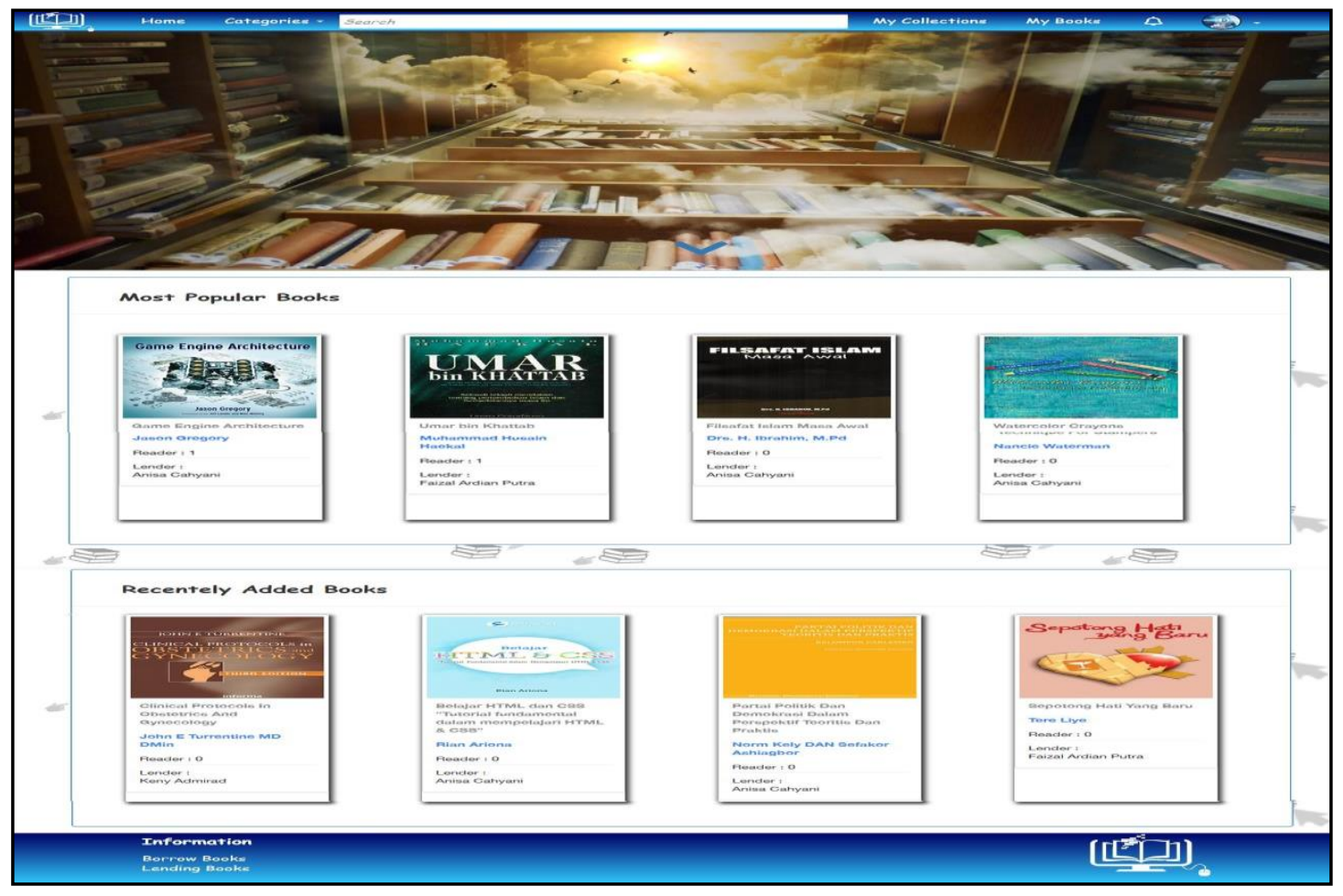

Gambar 2. Tampilan Halaman Index (Halaman Utama)

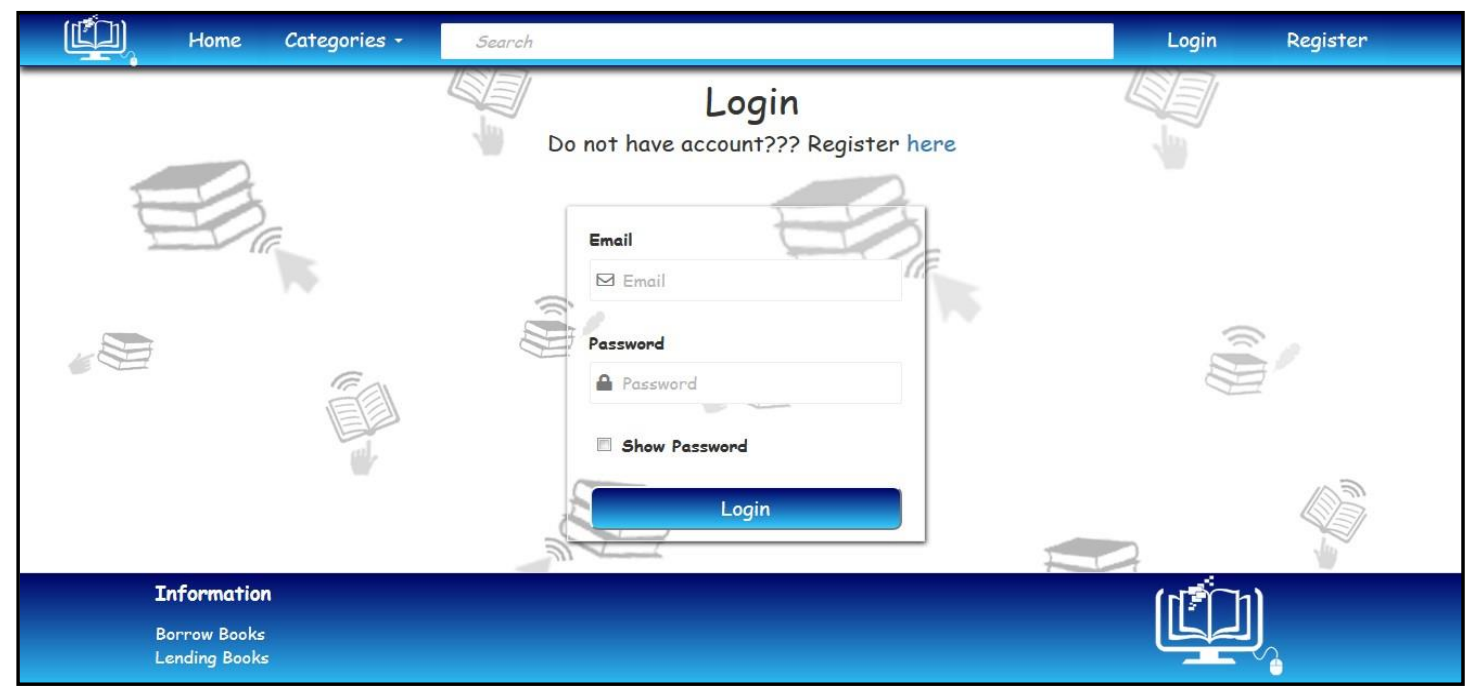

Gambar 3. Tampilan Halaman Login 


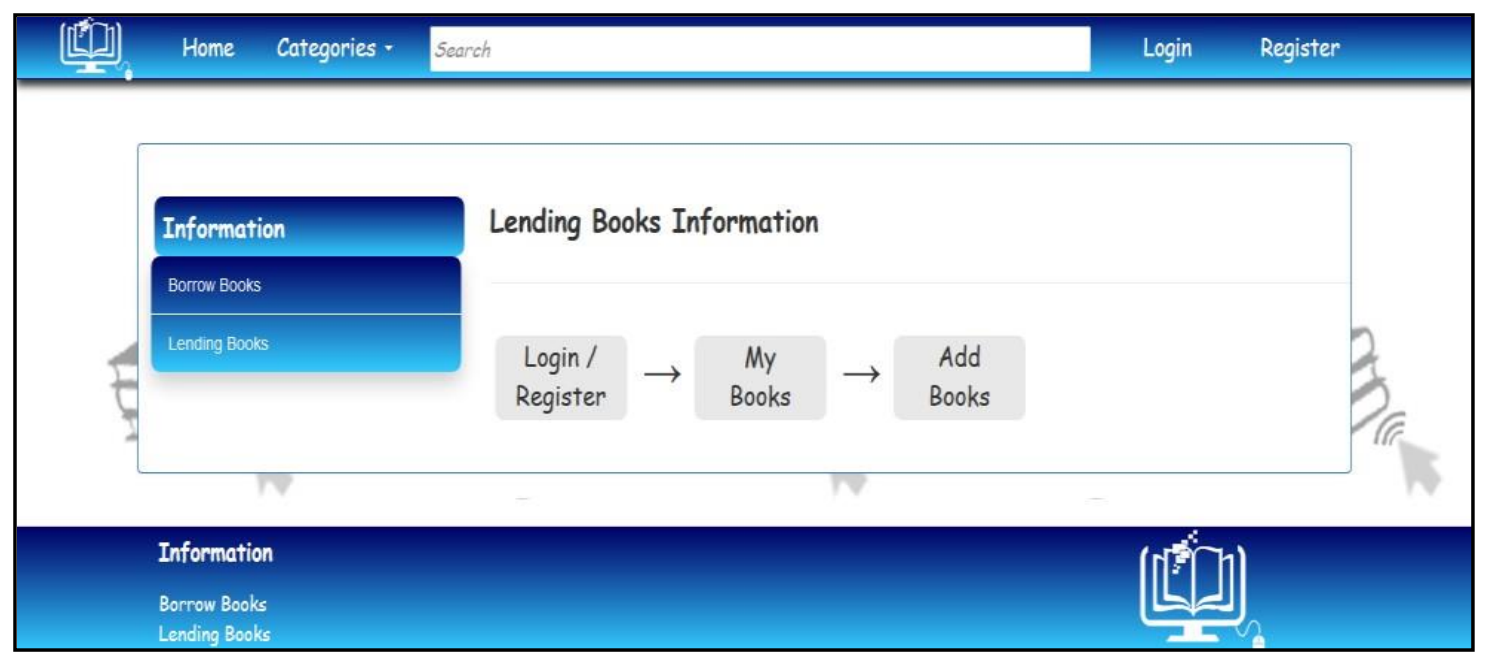

Gambar 4. Tampilan Information Lending Books

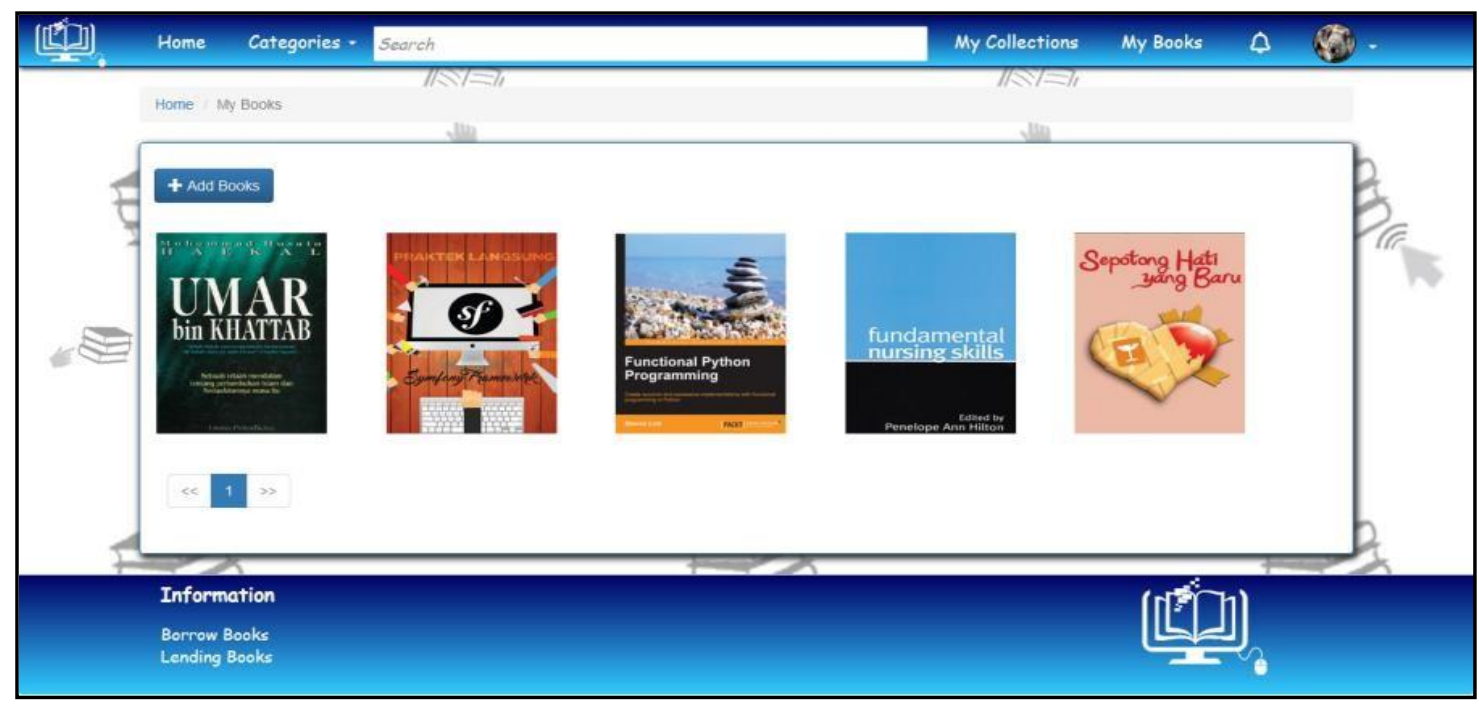

Gambar 5. Tampilan Halaman My Books

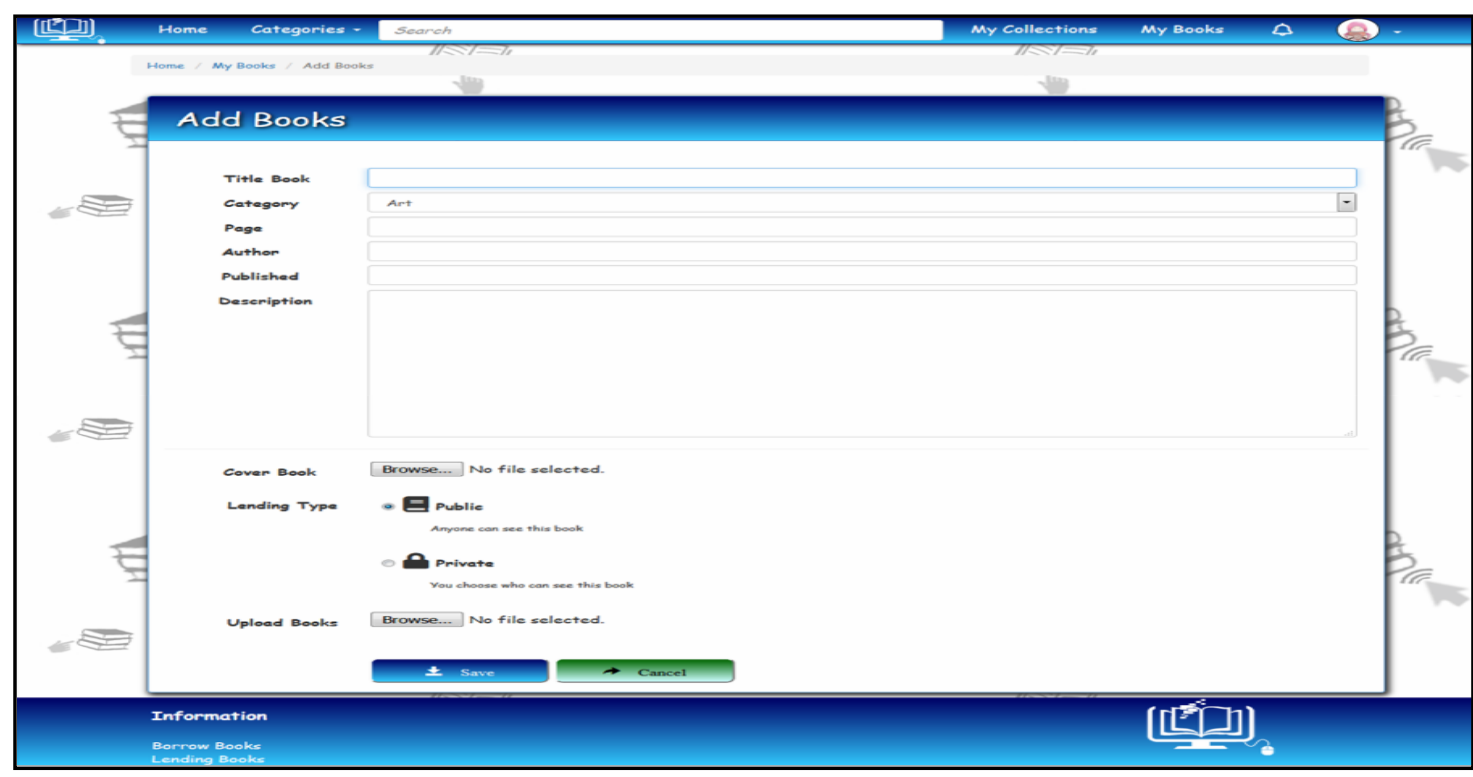

Gambar 6. Tampilan Halaman Index (Halaman Utama) 


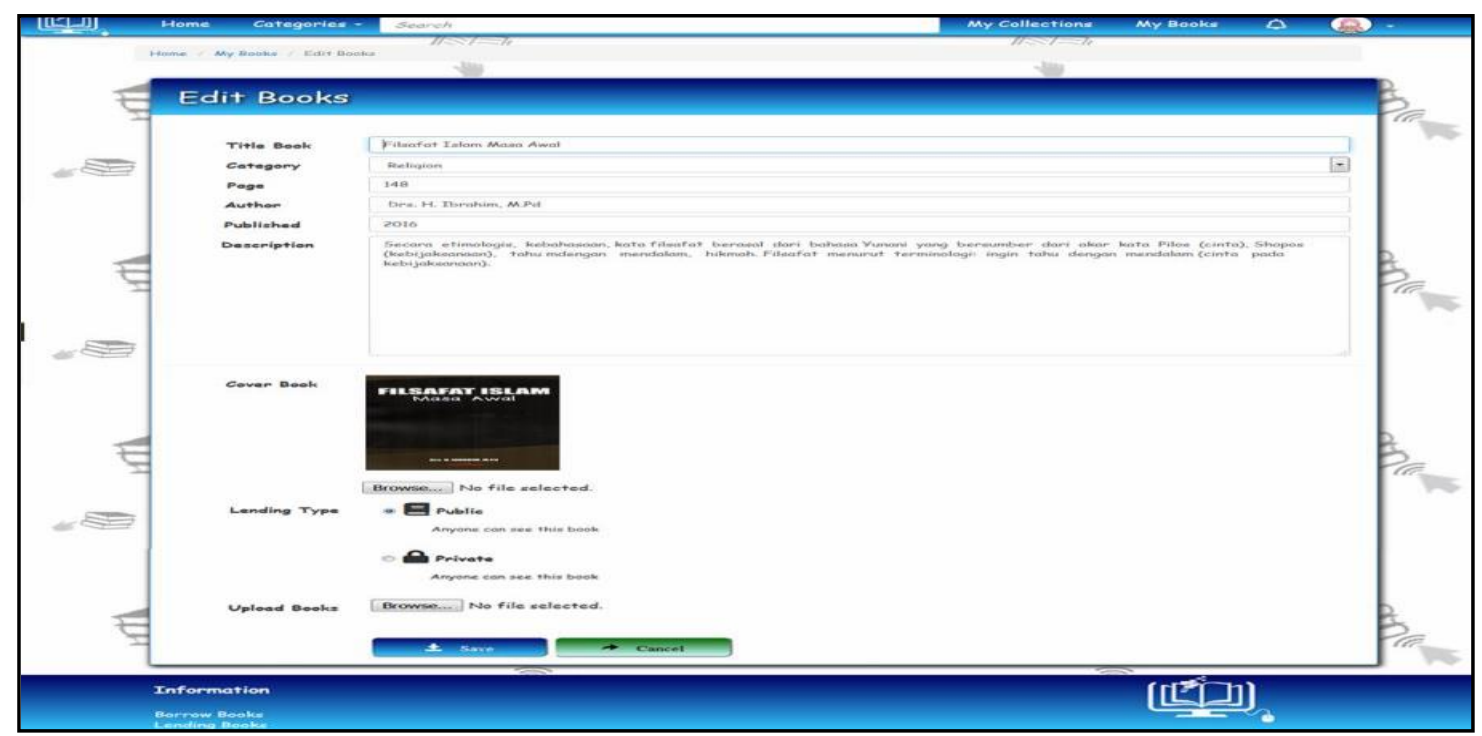

Gambar 7. Tampilan Halaman Edit Books

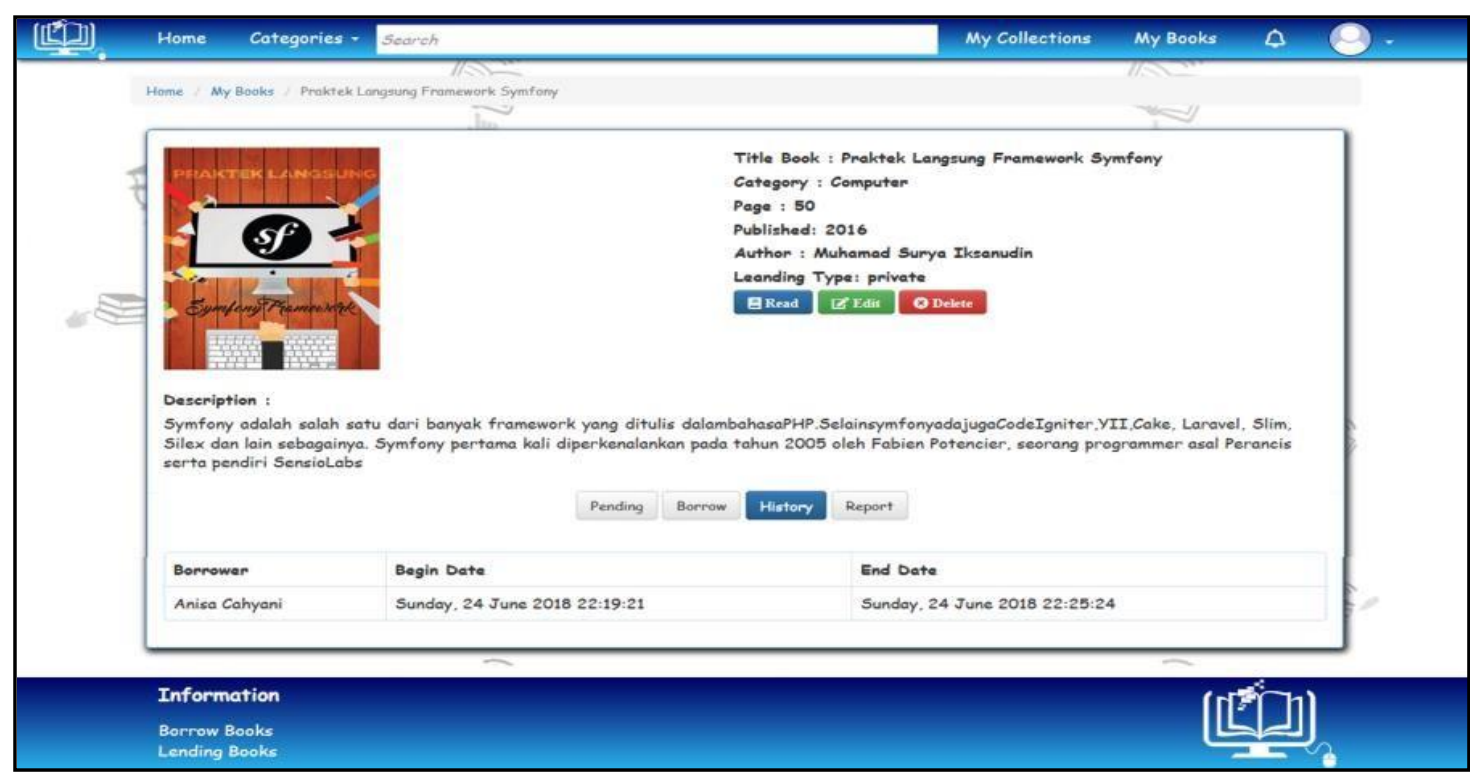

Gambar 8. Tampilan Halaman Detail Books History

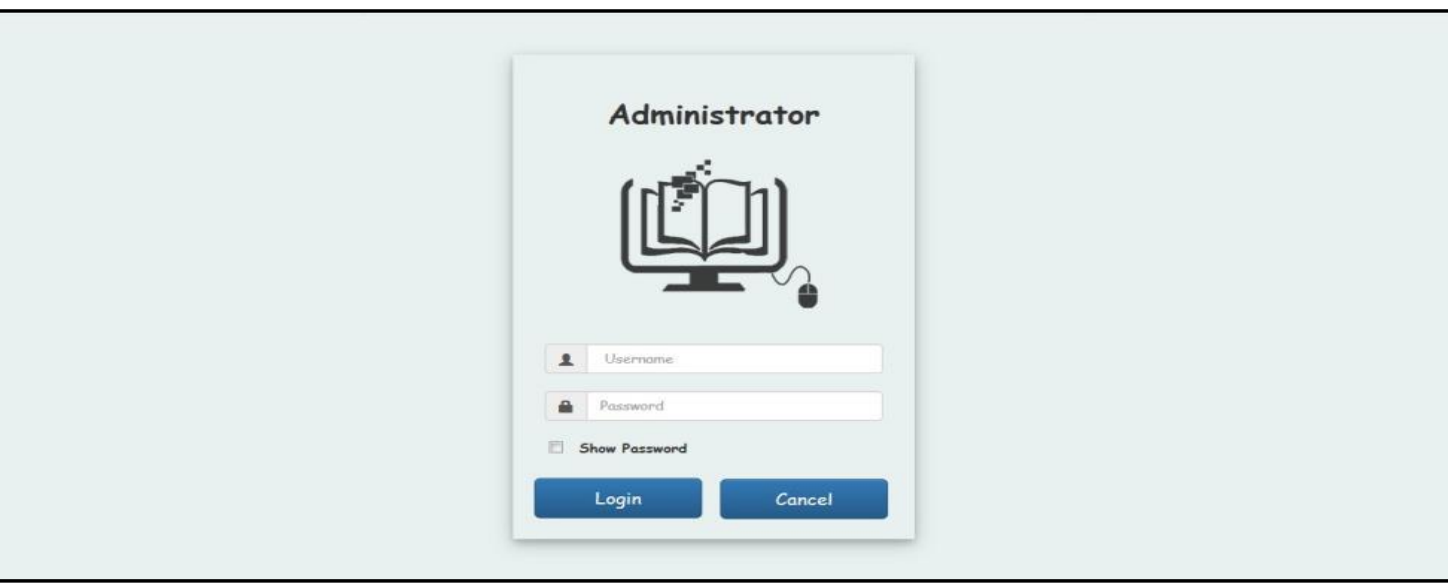

Gambar 9. Tampilan Halaman Login Admin 


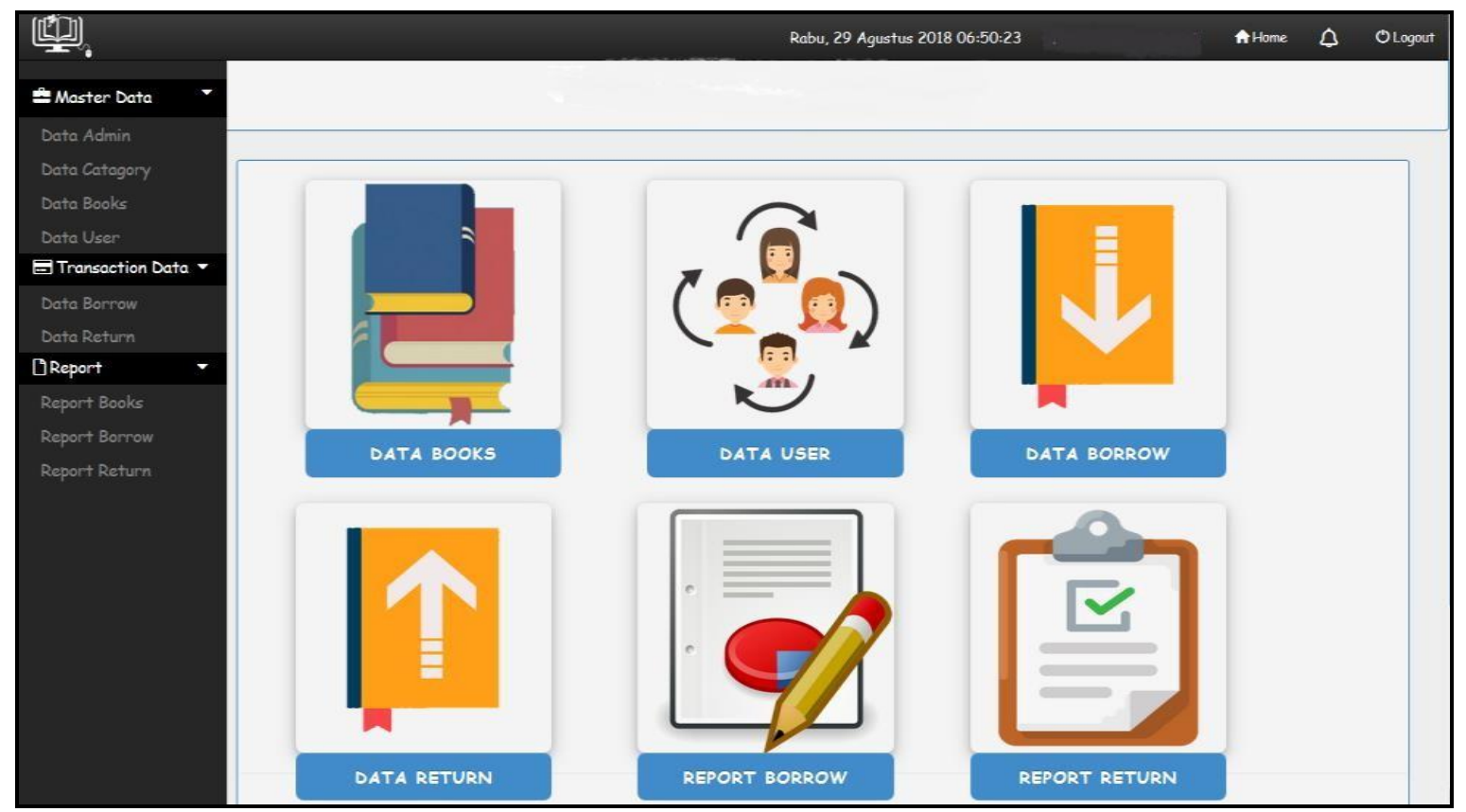

Gambar 10. Tampilan Halaman Home Admin

Dalam pengujian sistem peperpustakaan digital,menggunakan black box testing [10]. Hal ini dilakukan untuk mencari posisi kesalahan (error) dan memastikan keluaran yang dihasilkan sesuai dengan yang diinginkan. Pengujian yang kedua adalah white box testing yaitu menguji perangkat lunak dari segi desain dan kode program apakah mampu menghasikan fungsi-fungsi, masukan, dan keluaran yang sesuai dengan spesifikasi kebutuhan.

Table 3. Hasil perbandingan aplikasi dekstop dan aplikasi perpustakaan berbasis online

\begin{tabular}{clll}
\hline No & Perbandingan & $\begin{array}{l}\text { Perpustakaan } \\
\text { Konvensional }\end{array}$ & $\begin{array}{l}\text { Sistem Informasi Perpustakaan } \\
\text { Digital }\end{array}$ \\
\hline 1 & $\begin{array}{l}\text { Keakuratan } \\
\text { Data }\end{array}$ & Kurang Lengkap & $\begin{array}{l}\text { Data Lengkap tergantung } \\
\text { data yang di masukkan } \\
\text { petugas pustaka }\end{array}$ \\
2 & $\begin{array}{l}\text { Peminjaman } \\
\text { Buku }\end{array}$ & $\begin{array}{l}\text { Hanya bisa dibuka di } \\
\text { Perpustakaan }\end{array}$ & $\begin{array}{l}\text { Dapat di Akses dimana saja } \\
\text { dengan online untuk melihat } \\
\text { koleksi buku }\end{array}$ \\
3 & $\begin{array}{l}\text { Transaksi } \\
\text { Buku }\end{array}$ & $\begin{array}{l}\text { Data Kurang Akurat atas } \\
\text { transaksinya }\end{array}$ & $\begin{array}{l}\text { Data Akurat jumlah buku } \\
\text { yang di pinjam }\end{array}$ \\
4 & $\begin{array}{l}\text { Automatisasi } \\
\text { Perpustakaan }\end{array}$ & $\begin{array}{l}\text { Pencarian hanya } \\
\text { dilakukan di lingkungan } \\
\text { perpustakaan dan tidak } \\
\text { bisa diakses }\end{array}$ & $\begin{array}{l}\text { Memprcepat pengolahan } \\
\text { peminjaman dan } \\
\text { pengembalian, pencarian } \\
\text { katalog buku secara online, } \\
\text { secara online. }\end{array}$ \\
& & $\begin{array}{l}\text { review informasi buku secara } \\
\text { online. }\end{array}$ \\
\hline
\end{tabular}

Hasil Pengujian Dengan Menggunakan Use Terhadap 30 Responden Yang Terdiri Dari Siswa-siswi dan mahasiswa.

Table 4. Rekapitulasi hasil pengujian

\begin{tabular}{cccccc}
\hline No Pertanyaan & SS & S & KS & TS & STS \\
\hline 1 & 11 & 15 & 4 & 0 & 0 \\
2 & 9 & 17 & 4 & 0 & 0 \\
3 & 11 & 18 & 1 & 0 & 0 \\
\hline
\end{tabular}




\begin{tabular}{cccccc}
\hline 4 & 13 & 16 & 1 & 0 & 0 \\
5 & 10 & 17 & 3 & 0 & 0 \\
6 & 10 & 12 & 8 & 0 & 0 \\
7 & 11 & 15 & 4 & 0 & 0 \\
8 & 11 & 14 & 5 & 0 & 0 \\
9 & 10 & 19 & 1 & 0 & 0 \\
10 & 10 & 18 & 2 & 0 & 0 \\
11 & 11 & 18 & 1 & 0 & 0 \\
12 & 11 & 17 & 2 & 0 & 0 \\
13 & 7 & 19 & 4 & 0 & 0 \\
14 & 9 & 18 & 3 & 0 & 0 \\
15 & 12 & 14 & 4 & 0 & 0 \\
\hline
\end{tabular}

Table 5. Perhitungan skor total pengujian

\begin{tabular}{cccc}
\hline & JUMLAH & SKOR & JUMLAH X SKOR \\
SS & 156 & 5 & 780 \\
S & 247 & 4 & 988 \\
KS & 47 & 3 & 141 \\
TS & 0 & 2 & 0 \\
STS & 0 & 1 & 0 \\
& SKOR TOTAL & 1909 \\
\hline
\end{tabular}

Rumus untuk menghitung [10] : Skor Total / Skor Maksimal x 100\%

Skor maksimal didapat dari jumlah semua responden menjawab Sangat

Setuju dengan skor 5 , sehingga

Skor maksimal $=$ jumlah responden $\mathrm{x}$ jumlah soal kuesinoner $\times 5$

$$
\begin{aligned}
& =30 \times 15 \times 5 \\
& =2250
\end{aligned}
$$

Presentase $=1909 / 2250 \times 100 \%$

$$
=84,8 \%
$$

Berdasarkan persentase keseluruhan subyek maka diperoleh hasil respon adalah baik, yaitu $84,8 \%$. Pengujian ini dilaksanakan oleh siswa-siswi sekolah menengah atas dan mahasiswa yang sering ke perpustakaan. Dengan persentasi yang di hasilkan maka sistem informasi perpustakaan digital layak digunakan.

Tahap yang terakhir adalah evaluasi hasil pengujian perangkat lunak, pengujian blackbox testing (pengujian fungsionalitas) diperoleh bahwa semua proses yang dilakukan oleh user mampu berjalan dengan baik dan menghasilkan inputan yang sesuai dengan spesifikasi. Selanjutnya berdasarkan pengujian respon pengguna diproleh hasil baik atau sebesar $84,8 \%$ yang mana menyatakan bahwa sistem informasi perpustakaan telah memenuhi kebutuhan user. Pada pengujian kelayakan sistem hasil yang diperoleh bahwa sistem informasi perpustakaan digital layak diterapkan sebagai sistem untuk menunjang sistem informasi perpustakaan.

Tahap yang terakhir adalah Evaluasi hasil pengujian perangkat lunak, Pelaksanaan pengujian perangkat lunak berlangsung dengan baik dan lancar. Berdasarkan hasil pengujian whitebox testing diperoleh bahwa implementasi telah berhasil sehingga mendapatkan hasil yang sesuai. Kemudian pengujian blackbox testing diperoleh bahwa semua proses yang dilakukan oleh user mampu berjalan dengan baik dan menghasilkan inputan yang sesuai dengan spesifikasi. Selanjutnya berdasarkan pengujian respon pengguna atau pengujian lapangan diperoleh hasil

\begin{tabular}{|c|c|c|c|c|c|}
\hline No & Skenario pengujian & Test case & $\begin{array}{l}\text { Hal yang } \\
\text { diharapkan }\end{array}$ & $\begin{array}{l}\text { Hal yang } \\
\text { pengujian }\end{array}$ & Kesimpulan \\
\hline 1. & $\begin{array}{l}\text { Username dan } \\
\text { password tidak diisi } \\
\text { kemudian klik tombol } \\
\text { login }\end{array}$ & $\begin{array}{l}\text { Username: } \\
\text { (kosong) } \\
\text { Password: } \\
\text { (kosong) }\end{array}$ & $\begin{array}{l}\text { Sistem akan } \\
\text { menolak dan menampilkan } \\
\text { pesan "Please fill out this } \\
\text { field" pada textbox } \\
\text { username }\end{array}$ & $\begin{array}{l}\text { Sesuai } \\
\text { harapan, } \\
\text { dikarenakan } \\
\text { harus mengisi } \\
\text { seluruh data }\end{array}$ & Valid \\
\hline
\end{tabular}
baik yang mana menyatakan bahwa sistem telah memenuhi kebutuhan dari user.

Tabel 2. Hasil Pengujian blackbox testing Terhadap Halaman Login Admin 


\begin{tabular}{|c|c|c|c|c|c|}
\hline 3. & $\begin{array}{l}\text { Hanya mengisi } \\
\text { username dan } \\
\text { mengosongkan } \\
\text { pasword, Kemudian } \\
\text { klik tombol login }\end{array}$ & $\begin{array}{l}\text { Username: } \\
\text { admin } \\
\text { Password } \\
\text { (kosong) }\end{array}$ & $\begin{array}{l}\text { Sistem akan } \\
\text { menolak dan menampilkan } \\
\text { pesan "Please fill out this } \\
\text { field" pada textbox } \\
\text { password }\end{array}$ & Sesuai harapan & Valid \\
\hline 4. & $\begin{array}{l}\text { Hanya mengisi } \\
\text { password dan } \\
\text { mengosongkan } \\
\text { username, kemudian } \\
\text { klik tombol login }\end{array}$ & $\begin{array}{l}\text { Username: } \\
\text { (kosong) } \\
\text { Password: } \\
\text { admin (benar) }\end{array}$ & $\begin{array}{l}\text { Sistem akan } \\
\text { menolak dan menampilkan } \\
\text { pesan "Please fill out this } \\
\text { field" pada textbox } \\
\text { username }\end{array}$ & Sesuai harapan & Valid \\
\hline 5. & $\begin{array}{l}\text { Mengetikan salah } \\
\text { satu kondisi pada } \\
\text { username atau } \\
\text { password salah } \\
\text { kemudian klik tombol } \\
\text { login }\end{array}$ & $\begin{array}{l}\text { Username: } \\
\text { admin06 } \\
\text { (salah) } \\
\text { Password: } \\
\text { admin (benar) }\end{array}$ & $\begin{array}{l}\text { Sistem akan } \\
\text { menolak dan menampilkan } \\
\text { pesan "Info! Username or } \\
\text { Password Wrong" }\end{array}$ & Sesuai harapan & Valid \\
\hline 6. & $\begin{array}{l}\text { Mengetikan } \\
\text { username dan } \\
\text { password dengan data } \\
\text { yang benar kemudian } \\
\text { klik tombol login }\end{array}$ & $\begin{array}{l}\text { Username: } \\
\text { Admin (benar) } \\
\text { Password: } \\
\text { admin(benar) }\end{array}$ & $\begin{array}{l}\text { Sistem } \\
\text { menerima dan langsung } \\
\text { mengarahkan ke halaman } \\
\text { home admin }\end{array}$ & Sesuai harapan & Valid \\
\hline
\end{tabular}

Pada pengujian kelayakan sistem hasil yang diperoleh bahwa Sistem Informasi perpustakaan digital layak diterapkan sebagai sistem informasi perpustakaan untuk menunjang efektfitas dan efisiensi akademik. Perpustakaan merupakan salah satu sarana pembelajaran yang dapat menjadi sebuah kekuatan untuk mencerdaskan bangsa. Perpustakaan mempunyai peranan penting sebagai jembatan menuju penguasaan ilmu pengetahuan dan sekaligus menjadi tempat rekreasi yang menyenangkan, menyegarkan, dan mengasyikan. Oleh karena itu citra perpustakaan perlu dibangun agar dapat dikembangkan dengan baik. Dengan citra perpustakaan yang positif, perpustakaan akan mampu mengembangkan citra institusinya lebih lanjut, baik di dalam maupun di luar lembaga induknya. Dalam mengembangkan citra, perpustakaan berusaha meningkatkan layanannya yang sesuai dengan sistem manajemen mutu [1]. Paradigma lama tentang perpustakaan dengan berbagai kerumitannya dalam melakukan pengelolaan perpustakaan kini terhapus. Penerapan teknologi informasi di perpustakaan saat ini sudah menjadi sebuah ukuran untuk mengetahui tingkat kemajuan dari perpustakaan tersebut.

Pemanfaatan information and communication technology (ICT) sebagai sarana dalam meningkatkan kualitas layanan dan operasional telah membawa perubahan yang besar di perpustakaan. Perkembangan dari penerapan information and communication Technology (ICT) dapat diukur dengan telah digunakannya ICT sebagai sistem automasi perpustakaan serta telah diterapkannya perpustakaan digital (digital library). Sistem automasi perpustakaan merupakan pengintegrasian antara bidang pekerjaan administrasi, pengadaan, inventarisasi, katalogisasi, pengolahan, sirkulasi, pengelolaaan anggota perpustakaan, dan lain-lain. Digital library atau sistem perpustakaan merupakan konsep penggunaan internet dan teknologi informasi dalam manajemen perusahaan. Pengembangan perpustakaan digital bagi tenaga pengelola perpustakaan dapat membantu pekerjaan di perpustakaan melalui sistem yang sudah terkomputerisasi, sehingga proses pengelolaan perpustakaan lebih efektif dan efesien. Sedangkan bagi pengguna perpustakaan dapat membantu mencari sumber-sumber informasi yang di inginkan dengan menggunakan katalog online yang dapat di akses melalui internet, sehingga pencarian informasi dapat dilakukan kapanpun dan dmanapun.

Dengan dikembangkan perpustakaan yang berbasis pada teknologi informasi dan komunikasi (ICT) baik dalam sistem automasi perpustakaan maupun digital library, diharapkan dapat memberikan kenyamanan kepada anggota perpustakaan dan memberikan kemudahan kepada tenaga pustakawan, baik dalam pelayanan maupun pengolahan data serta dapat meningkatkan citra perpustakaan dalam memberikan layanan kepada pengguna perpustakaan.

Berdasarkan permasalahan tersebut peneliti melakukan kajian terhadap penelitian terkait dengan masalah yang ditemukan. Pengembangan teknologi merupakan salah satu cara untuk mengatasi masalah tersebut, pengembangan teknologi yang dimaksud adalah mengembangkan perangkat lunak sistem informasi terpadu. Dari hasil temuan kajian tersbut peneliti termotivasi untuk mengembangkan sistem informasi melalui penelitian dengan judul "Membangun Sistem Informasi Perpustakaan Digital Berbasis Web". 
Metode pengembangan perangkat lunak Pengembangan Sistem Informasi Perpustakaan Digital ini mengacu pada metode SDLC (Software Development Life Cycle). Model yang digunakan pada metode SDLC merupakan model waterfall dan permodelan menggunakan diagram UML (Unified Modelling Languange). Adapun tahap yang dilakukan dalam penelitian sesuai dengan model waterfall adalah tahap analisis, perancangan, implementasi dan pengujian. Tahap pertama dalam model waterfall adalah analisis kebutuhan (requirements analysis and definition) perangkat lunak. Analisis kebutuhan dilakukan untuk mengetahui kebutuhan dari proses pengembangan perangkat lunak. Selanjutnya adalah tahap perancangan (System dan Software Design) tahap perancangan perangkat lunak dibuat berdasarkan kebutuhan pengguna perpustakaan. Hasil rancangan perangkat lunak yang dibuat akan menjadi dasar dalam melakukan implementasi perangkat lunak.

Sistem Informasi Perpustakaan Digital telah berhasil diselesaikan dan telah berhasil di melalui tahap pengujian. Pengujian respon pengguna menunjukan nilai sebesar $84,8 \%$ yang menyatakan bahwa semua kebutuhan dari pengguna telah terpenuhi. Pada pengujian kelayakan sistem informasi Perpustakaan Digital dinyatakan layak karena semua data yang diinputkan oleh user sesuai dengan yang dihasilkan oleh sistem

Berdasarkan hasil dari beberapa pengujian yang dilakukan dapat dinyatakan bahwa tujuan penelitian sudah tercapai. Hal tersebut dilihat dari hasil pengujian struktural (whitebox testing), pengujian fungsional (blackbox testing), pengujian lapangan (respon pengguna), pengujian kelayakan sistem yang mendapatkan hasil yang baik. Dari hasil yang sudah didapatkan pengembangan sistem Informasi Perpustakaan Digital.

\section{SIMPULAN DAN SARAN}

Berdasarkan pemaparan di atas hasil penelitian dan pengembangan dapat di Tarik beberapa simpulan sebagai berikut: (1) Berdasarkan persentase keseluruhan subyek maka diperoleh hasil respon adalah baik, yaitu 84,8\%. Pengujian ini dilaksanakan oleh siswa-siswi sekolah menengah atas dan mahasiswa yang sering ke perpustakaan. Dengan persentasi yang di hasilkan maka sistem informasi perpustakaan digital layak digunakan. Setelah menganalisa hasil data tersebut, responden yang memberikan jawaban menyukai penerapan perpustakaan digital berjumlah $84,8 \%$, maka dapat di katakan bahwa pada umumnya siswa siswi menyukai system perpustakaan digital. (2) Website ini dapat mempermudah user dalam meminjam dan mengembalikan buku dimana pun dan kapan pun secara online. Sehingga user tidak perlu mengeluarkan biaya, waktu dan tenaga dalam meminjam dan mengembalikan buku. (3) Dengan adanya fasilitas mengelolah buku, user tidak hanya bisa membaca buku tetapi user juga dapat menambah, mengubah dan menghapus buku tersebut.(4) Website ini juga menyediakan fasilitas notifikasi yang berguna untuk memberi tahu user mengenai peminjaman buku yang bersifat private oleh user dan menyediakan fitur laporan dengan grafik yang dapat membantu user dalam melihat perkembangan peminjaman dan pengembalian buku.

Beberapa saran yang dapat digunakan oleh digital library berbasis online untuk mendukung sistem yang diusulkan serta pengembangan apa saja yang dapat dilakukan pada waktu yang akan mendatang adalah sebagai, berikut: (1) Diperlukan ketelitian dari user dalam memasukan data agar tidak terjadi kesalahan dalam memasukan data. (2) Mengingat pentinnya data-data yang dipergunakan, sebaiknya perlu dilakukan back-up data kedalam hardisk atau flashdisk untuk mengantisipasi kehilangan maupun kerusakan file. (3) Perlu dilakukannya pembaharuan, pemeliharaan dan perawatan secara berkala terhadap perangkat lunak (software) dan perangkat keras (hardware). (4) Sebagai pengembangan program untuk kedepannya dibutuhkan preview buku. Dimana user dapat mengetahui sebagian isi buku sebelum meminjamnya dan sebagai media pertimbangan user apakah ingin meminjam buku tersebut atau tidak. (5) Dibutuhkan fitur komentar pada buku agar para peminjam buku dapat meninggalkan kesan atau pesan yang nantinya akan dibaca oleh peminjam lainnya sebagai bahan acuan pertimbangan pada peminjaman buku.

\section{DAFTAR PUSTAKA}

[1] Mirawati dan Purnia, D. S. (2015). Pembangunan Sistem Informasi Perpustakaan Pada Sekolah Menengah Pertama Negeri 5 Ciamis. Jurnal Informatika, 2(2), 385-394.

[2] Prayitno, A dan Safitri, Y. (2015). Pemanfaatan Sistem Informasi Perpustakaan Digital Berbasis Website Untuk Para Penulis. IJSE - Indonesian Journal on Software Engineering, 1(1).

[3] Pahlevi, Said Mirza. (2013). Tujuh Langkah Praktis Pembangunan Basis Data. Jakarta: PT Elex Media Komputindo.

[4] Sasongko, A. (2015). Rancangan Sistem Informasi Perpustakaan Digital Perguruan Tinggi Jurnal Khatulistiwa Informatika, vol 3(no 2), 124-133.

[5] Rawung, Frangky. (2017). Buku Pintar Aplikasi SMS dengan PHP dan MySQL. Yogyakarta: 
Gava Media.

[6] Fitriani, E., Indrajit, R. E., dan Aryanti, R. (2017). Penerapan Model Information Retrieval Untuk Pencarian Konten Pada Perpustakaan Digital, XV(2), 170-176.

[7] Abdulloh, Rohi. (2016). Easy \& Simple Web Programming. Jakarta: PT Elex Media Komputindo.

[8] Booch, G., Rumbaugh, J., \& Jacobson, I. (1998). Unified Modeling Language User Guide. Addison Wesley.

[9] Maturidi, Ade Djohar. (2014). Metode Penelitian Teknik Informatika. Yogyakarta: Deepublish.

[10] Andriansyah, Doni. (2016). Sistem Informasi Pendaftaran Event Dengan PHP Untuk Panduan Skripsi. Cirebon: CV. ASFA Solution.

[11] Berander, P., Damm, L. O., Eriksson, J., Gorschek, T., Henningsson, K., Jonsson, P., et al. (2005). Software Quality Attributes and trade-offs. Blekinge Institute of Technology.

[12] Setiawan, Didik. (2017). Buku Sakti Pemograman Web: HTML, CSS, PHP, MySQL \& Javascript. Yogyakarta: START UP. 